\section{Wann ist's passiert? \\ Gentest datiert HIV-Infektion}

> Für die Datierung einer HIV-Infektion außerhalb der akuten Phase muss nicht länger der Tag der Diagnose herhalten. Mit einer einfachen Methode gelang es Forschern, einen genaueren Hinweis für den Ansteckungszeitpunkt zu liefern. Für Resistenztests analysierten sie die Gene der HI-Viren einzelner Patienten aus der Schweizerischen HIV-Kohortenstudie. Dabei stellten sie fest, dass die Vielfalt im Genpool der Viren nach der Infektion über acht Jahre linear zunimmt - und zwar um $0,2 \%$ pro Jahr. Diese „Unschärfe“ im Resistenztest bietet so für einige Jahre einen Hinweis auf den tatsächlichen Zeitpunkt der Infektion. Etwa zehn Jahre nach der Infektion stagniert dann der genetische Wandel der Viren. Eine genaue Datierung der Infektion trauen die Forscher ihrer Methode allerdings noch nicht zu. Ob eine Infektion aber bereits über ein Jahr zurückliegt, können sie mit 99\%iger Sicherheit sagen.

Kouyos RD et al, Clin Infect Dis 2011 (online first)

Wichtig für die Therapie - Wann hat sich der Patient infiziert?

\section{Tbc-Impfstoff für danach}

\Der neuartige Tuberkulose-Impfstoff H56 soll Patienten künftig nicht nur vor einer Neuinfektion schützen, sondern auch danach. Die dänischen Entwickler setzen dabei auf das Protein Rv2660c, welches in der latenten Phase einer Tuberkuloseinfektion exprimiert wird. Anders als bisherige Impfstoffe, die gegen in der Frühphase exprimierte Antigene wie Ag85B immunisieren, konnte das neue Vakzin im Mausmodell bereits eine Reaktivierung der Tuberkulose unterbinden. Klinische Studien sollen jetzt folgen. Aagaard C et al, Nature Med 2011 (online first)

\section{Bakterium liebt Menschenblut}

> Forscher haben herausgefunden, weshalb Staphylococcus aureus den Menschen zum Lieblingsopfer erkoren hat. Wie viele andere Bakterien auch benötigt der Keim für sein Wachstum Eisen. Und das besorgt er sich bei invasiven Infektionen aus dem roten Blutfarbstoff. Dabei bevorzugt $S$. aureus offenbar menschliches Hämoglobin, weil er daran besonders gut binden kann. So waren genetisch veränderte Mäuse, die menschliches Hämoglobin bilden, anfälliger für S.-aureus-Infektionen als ihre Artgenossen.

Pishany G et al, Cell Host Microbe 2010, 8:544

\title{
Chlamydien-Infektionen in der EU nehmen zu
}

\begin{tabular}{|c|c|c|c|}
\hline 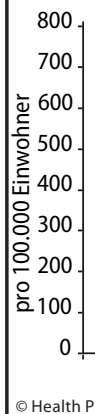 & 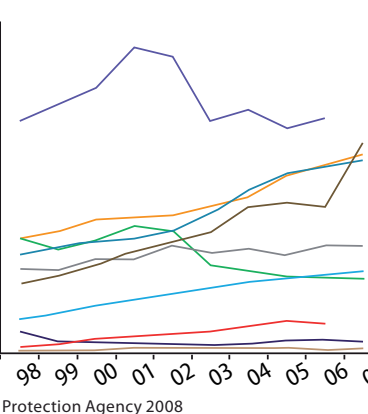 & $\begin{array}{l}\text { Island } \\
\text { Schweden } \\
\text { Norwegen } \\
\text { Dänemark } \\
\text { Finnland } \\
\text { Großbritannien } \\
\text { Estland } \\
\text { Irland } \\
\text { Lettland } \\
\text { Slovenien }\end{array}$ & $\begin{array}{l}\text { Chlamydien-Infektionen sind } \\
\text { besonders bei jungen Frauen auf } \\
\text { dem Vormarsch. Die europäische } \\
\text { Gesundheitsbehörde ECDC } \\
\text { schätzt die Zahl infizierter Frauen } \\
\text { und Männer in der EU bereits } \\
\text { auf 2,5 Mio. In Deutschland sind } \\
\text { Chlamydien allerdings nicht } \\
\text { meldepflichtig. } \\
\text { Pressemitteilung BVF, Januar } 2011\end{array}$ \\
\hline
\end{tabular}

\section{Hatschi? Wohlsein!}

Der Mensch ist nie allein - auch wenn er sich vielleicht manchmal so fühlt. In Wahrheit sind Billionen von Kleinstlebewesen unsere ständigen Begleiter, und das in den meisten Fällen zu unserem Segen. Leider allerdings auch zu unserem Ärgernis und manchmal sogar bis hin zur Lebensgefahr: Grund genug, in dieser CME-Ausgabe den Infektionen einen Schwerpunkt zu widmen. Den Anfang macht die Grippe - und zwar in Form der Prophylaxe. Wer sollte geimpft werden? Was bringt die Grippeimpfung wirklich? Wie schlägt in dieser Saison das H1N1-Virus zu? Antworten darauf finden Sie bei uns ebenso wie eine mögliche Erklärung für den Zusammenhang zwischen Influenza und Myokardinfarkt. Daneben widmen wir uns dem PingPong-Effekt bei Genitalwarzen, dem schwächelnden Immunsystem im Alter und dem Procalcitonin-Test, mit dem Sie bei Atemwegsinfektionen gut herausfinden können, ob eine Antibiotika-Therapie indiziert ist. Eine informative Lektüre wünscht Ihnen

\section{Souja Leupiurl.}

www.SpringerMedizin.de

\section{Top gelesen von \\ Hausårzten \\ Wann sind Opioide (k)eine \\ Option? \\ Einfache Mittel gegen senile \\ Bettflucht \\ Popeye-Diät wirkt: Spinat stärkt \\ Muskeln!}

Loggen Sie sich ein und nutzen Sie die Fülle von Beiträgen auf SpringerMedizin.de! Die oben genannten Artikel finden Sie, in dem Sie die Schlagworte in die Suche eingeben.

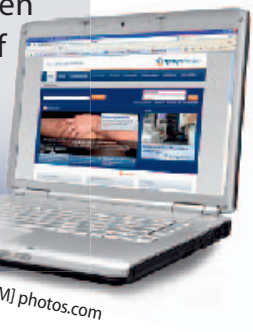

